\title{
Concurrent Sickle Cell Anemia and $\alpha$-Thalassemia

\author{
Effect on Pathological Properties of \\ Sickle Erythrocytes
}

\author{
Stephen H. Embury, Margaret R. Clark, Gladys Monroy, \\ and Narla Mohandas \\ With the technical assistance of Robert Hoesch \\ Hematology Division of the Medical Service, San Francisco \\ General Hospital and the University of California, San Francisco, \\ The Northern California Comprehensive Sickle Cell Center, \\ Department of Laboratory Medicine, University of California, \\ San Francisco, California 94110
}

bstract. The concurrence of sickle cell anemia and $\alpha$-thalassemia results in less severe hemolytic anemia apparently as a result of reduced intraerythrocytic concentration of hemoglobin $\mathrm{S}$ and its retarded polymerization. We have evaluated the effect of $\alpha$-globin gene number on several interrelated properties of sickle erythrocytes (RBC) that are expected to correlate with the hemolytic and rheologic consequences of sickle cell disease. The irreversibly sickled cell number, proportion of very dense sickle RBC, and diminished deformability of sickle RBC each varied directly with $\alpha$-globin gene number. Sickle $\mathrm{RBC}$ density was a direct function of the mean corpuscular hemoglobin concentration (MCHC). Even in nonsickle $\mathrm{RBC}, \alpha$-globin gene number varied directly with $\mathrm{RBC}$ density.

Despite differences in $\alpha$-globin gene number, sickle $\mathrm{RBC}$ of the same density had the same degree of deformability and dehydration. These data indicate that the fundamental effect of $\alpha$-thalassemia is to inhibit the generation of sickle RBC having high density and $\mathrm{MCHC}$, and that the other beneficial effects of sickle $\mathrm{RBC}$ are secondary to this process.

The less consistent effect on overall clinical severity reported for subjects with this concurrence may reflect

Portions of these studies were presented at the Annual Meeting of the American Society of Hematology, San Antonio, Texas, December 1981.

Address reprint requests to Dr. Embury, Building 100, Room 263, San Francisco General Hospital, San Francisco, CA 94110.

Received for publication 8 June 1983 and in revised form 15 September 1983.

J. Clin. Invest.

(C) The American Society for Clinical Investigation, Inc.

$0021-9738 / 84 / 01 / 0116 / 08 \quad \$ 1.00$

Volume 73, January $1984,116-123$ an undefined detrimental effect of $\alpha$-thalassemia, possibly on the whole blood viscosity or on sickle RBC membranemediated adherence phenomena.

\section{Introduction}

Polymerization of deoxyhemoglobin $\mathrm{S}$ is fundamental to each of the clinical manifestations of sickle cell anemia $(1,2)$. Because of the profound influence of the concentration of hemoglobin $(\mathrm{Hb})^{1} \mathrm{~S}$ on both the kinetics (3) and extent (4) of polymerization, factors that influence the intraerythrocytic concentration of $\mathrm{Hb}$ $\mathrm{S}$ are likely to determine, at least in part, the widely variable clinical expression (5) of sickle cell disease. Among these factors, $\alpha$-thalassemia is of particular interest because of its high prevalence in the Black population (6). We have previously reported that the concurrence of $\alpha$-thalassemia with homozygous sickle cell anemia results in decreased intraerythrocytic concentration of $\mathrm{Hb} \mathrm{S}$ in mature erythrocytes (RBC) and in less severe hemolytic anemia (7). This effect has been confirmed by others (8) and is apparently related to a decreased amount of $\mathrm{Hb} \mathrm{S}$ polymer found within these sickle RBC (9). The longer life expectancy reported for this group of patients (10) suggests that the cumulative pathophysiology of sickle cell disease is directly related to the degree of polymerization. However, certain complications of sickle cell disease appear to be unimproved (8) or even more severe $(11,12)$ in the presence of higher $\mathrm{Hb}$ levels and $\alpha$-thalassemia. Thus, factors other than the general degree of polymerization appear to be involved in determining the clinical variability of sickle cell disease.

In these further studies of concurrent $\alpha$-thalassemia and sickle cell anemia, we have evaluated the effect of $\alpha$-globin gene number on certain pathologic properties of sickle $R B C$ that are

1. Abbreviations used in this paper: $\mathrm{DI}$, deformability index; Hb, hemoglobin; ISC, irreversibly sickled cells; MCHC, mean corpuscular hemoglobin concentration; RBC, erythrocytes. 
determinants of hemolysis and rheology: the irreversibly sickled cell (ISC) number; the proportion of very dense RBC; and the deformability of sickle RBC (13-18). We have also characterized the primary mechanism by which $\alpha$-globin gene number affects these pathologic properties of sickle RBC. The results are reported herein.

\section{Methods}

Hematologic data. Complete blood counts and erythrocyte indices were performed on the Coulter model S (Coulter Electronics, Inc., Hialeah, FL), hemoglobin solubility testing by using a commercial assay (Sickle Sol, DADE Division, American Hospital Supply Corp., Miami, FL), and hemoglobin electrophoresis on alkaline cellulose acetate and on acid citrate agar (19). The diagnosis of sickle cell anemia was confirmed by family studies, when possible.

Determination of $\alpha$-globin genotype. The $\alpha$-globin genotypes characteristic of the normal nonthalassemic $(\alpha \alpha / \alpha \alpha)$, silent carrier $(-\alpha / \alpha \alpha)$, or $\alpha$-thalassemia trait $(-\alpha /-\alpha)$ conditions in the Black population (6) were determined by Southern blot hybridization restriction endonuclease mapping (20) of genomic DNA extracted from peripheral blood leukocytes. The hybridization probe was the $\alpha$-globin gene-specific plasmid JW 101 (21) that was labeled with ${ }^{32} \mathrm{P}(22)$.

One subject with microcytosis had replete iron stores and lacked diagnostic evidence of sickle- $\beta$-thalassemia. We suspected the deletion of two $\alpha$-globin genes despite normal gene mapping results. The presence of $\alpha$-thalassemia trait was shown by using Triton X-urea-polyacrylamide electrophoresis of labeled globin chains (23) followed by autofluorography and densitometric tracing to determine that the $\alpha$ :non- $\alpha$ synthetic ratio was 0.57 . The presence of heterozygous $\alpha$-thal- $1(--/ \alpha \alpha)$ was confirmed by using blot hybridization restriction mapping (20) of DNA $5^{\prime}$ to the $\alpha$-loci to detect $\zeta$-specific fragments characteristic of an $\alpha$-thal- 1 deletion (24).

ISC counting. The ISC number was determined as the percentage of elongated (length $>2 \times$ width) or angularly contoured RBC among 500 RBC examined by phase-contrast microscopy after the cells were well-oxygenated for $30 \mathrm{~min}$ and fixed in $3 \%$ gluteraldehyde- $0.05 \mathrm{M}$ phosphate buffer, pH 7.4 (25). Samples containing sharply spiculated $\mathrm{RBC}$, which were presumed to be reversibly sickled and thus inadequately oxygenated, were excluded from analysis. To minimize subjective variation in this value, all counts were performed by a single experienced observer (Dr. M. Clark).

"Dense" cell determination. The proportion of "dense" RBC was established by cyanmethemoglobin determination (19) of the fraction of hemoglobin found in a dense $(d=1.1056 \mathrm{~g} / \mathrm{ml})$ cushion of Stractan II (St. Regis Paper Co., NY) in a 100- $\mu 1$ microhematocrit tube (Corning Glass Works, Corning, NY) after $20 \mathrm{~min}$ of centrifugation in a microhematocrit centrifuge (International Equipment Co., Needham Heights, MA) (25).

Cell deformability determination. A laser diffraction viscometer, the ektacytometer (26), was used to determine the deformability of sickle cells. The deformability index (DI) is obtained from an image analysis system that measures light intensity at two positions of the elongated laser diffraction patterns of cell suspensions that have reached the plateau of maximum deformation under shear stress; DI equals $A-B / A+B$ when $A$ and $B$ are light intensities at points on the long and the short axis, respectively, of the diffraction pattern. The measured DI of RBC suspensions that contain ISC are somewhat depressed due to the ISC aligning perpendicular to the deforming $\mathrm{RBC}$ (27). For this reason, the DI of ISC-containing RBC suspensions do not reflect quantitatively the deformabilities of different suspensions, but they do reflect relative differences in deformability of different samples. To determine the role of cellular dehydration in determining RBC deformability, the DI of each sample was measured not only in an isotonic $(290$ mosM) medium, but also in two hypotonic ( 210 and 150 mosM) media in which the RBC became more hydrated than at 290 mosM. The percent DI for each measurement was expressed as a comparison of the DI at each osmolality with the DI of normal control RBC in the isotonic medium.

$R B C$ density and mean corpuscular hemoglobin concentration (MCHC) determination. Direct analysis of the effect of $\alpha$-globin gene number on RBC density was performed by using twelve-step analytic Stractan gradients that consisted of $1-\mathrm{ml}$ fractions spanning a density range of $1.120-1.070 \mathrm{~g} / \mathrm{ml}$ in equal increments. $125 \mu \mathrm{l}$ of packed $\mathrm{RBC}$ from $\mathrm{Hb}$ SS subjects and from a control subject with $\mathrm{Hb} \mathrm{AA}$ and four $\alpha$-globin genes were layered above these gradients as a dilute suspension to fill the $17-\mathrm{ml}$ tube, and the gradients were centrifuged in a SW 27 rotor (Beckman Instruments, Inc., Fullerton, CA) at 20,000 rpm for 30 min at $15^{\circ} \mathrm{C}$. To quantify the distribution of $\mathrm{RBC}$ at the various densities, the RBC from each fraction were isolated, washed, fixed in $0.5 \%$ gluteraldehyde-Isoton (Coulter Electronics), and counted on a Coulter model B cell counter (Coulter Electronics).

To verify a relationship between $\mathrm{RBC}$ density and $\mathrm{MCHC}$, we also separated RBC from these subjects on eight-step preparative Stractan gradients that encompassed densities of $1.120-1.074 \mathrm{~g} / \mathrm{ml}$, the most dense four steps of which consisted of increments half the density range of the least dense four steps. The MCHC of the RBC from each fraction was calculated from spun hematocrits and $\mathrm{Hb}$ concentrations that were determined by the cyanmethemoglobin method (19).

To assess the direct effect of $\alpha$-globin gene number on the RBC density in the absence of the abnormal water and cation fluxes inherent with sickle $\operatorname{RBC}(28,29)$, we performed density gradient analysis on $\mathrm{RBC}$ from representative subjects homozygous for $\mathrm{Hb} \mathrm{A}$ who have differing numbers of $\alpha$-globin genes. In these studies, we used elevenstep analytic Stractan gradients of which the densities spanned from 1.106 to $1.060 \mathrm{~g} / \mathrm{ml}$ in equal increments above a cushion with a density of $1.120 \mathrm{~g} / \mathrm{ml}$.

Effect of $\alpha$-globin gene number vs. RBC density on $R B C$ deformability. To determine whether the effect of $\alpha$-globin gene number on sickle RBC deformability could be explained completely on the basis of its effect on RBC density and MCHC, we compared the deformabilities of equal density subpopulations of RBC from sickle subjects with four, three, and two $\alpha$-globin genes with the deformabilities of the total RBC from the same subjects. The equal density subpopulations were obtained by using three-step preparative Stractan gradients (densities 1.097, 1.092, and $1.087 \mathrm{~g} / \mathrm{ml}$ ) to isolate the RBC fractions trapped between the two least dense Stractan layers. For these analyses, we used osmotic gradient ektacytometry, in which the RBC deformability is determined while the $\mathrm{RBC}$ are exposed to a linear osmolality gradient (30).

Statistical methods. Data were analyzed by Fisher's least significant difference test (31). Certain of the data was displayed by using boxplots (32) in which the box contains the middle $50 \%$ of the data (the interquartile range), the asterisk within the box indicates the median of the data, and the rest of the data points, except for outliers, reside within the two crosses. An outlier represented by an open circle is any data point that is further than one interquartile distance from the extremities of the box; an outlier represented by an asterisk is any data point that is further than 1.5 times the interquartile distance from the extremities of the box. 


\section{Results}

Effect of $\alpha$-globin gene number on ISC counts. The nonthalassemic group of sickle cell anemia subjects had significantly $(P<0.05)$ larger fractions of ISC than the combined groups with three and two $\alpha$-globin genes (Fig. 1). This finding is in agreement with the data of Higgs et al. (8) and is compatible with previous reports of more severe anemia in the nonthalassemic group $(7,8)$ and with the known association between ISC numbers and severity of anemia (14).

Effect of $\alpha$-globin gene number on proportion of "dense" sickle $R B C$. The nonthalassemic group of subjects had significantly $(P<0.05)$ larger proportions of "dense" RBC than either of the groups with $\alpha$-thalassemia (Fig. 2); this finding is again compatible with previous reports on the severity of anemia $(7,8)$ and with the close correlation between ISC numbers and proportion of dense RBC (25).

Effect of $\alpha$-globin gene number on sickle $R B C$ deformability. Assessment of deformability of RBC in isotonic medium (290 mosM) revealed that sickle RBC from nonthalassemic subjects had significantly $(P<0.05)$ lower percent DI than those from subjects of either group with $\alpha$-globin gene deletion, and that sickle $\mathrm{RBC}$ in general had significantly lower percent DI than normal control RBC (Fig. 3).

When cellular uptake of water was induced osmotically by suspending sickle RBC in 210-mosM medium, deformability of $\mathrm{RBC}$ from each subject was improved over that measured at isotonicity, and RBC from the nonthalassemic subjects remained significantly $(P<0.05)$ less deformable than RBC from either group with $\alpha$-thalassemia (Fig. 3). The improved percent

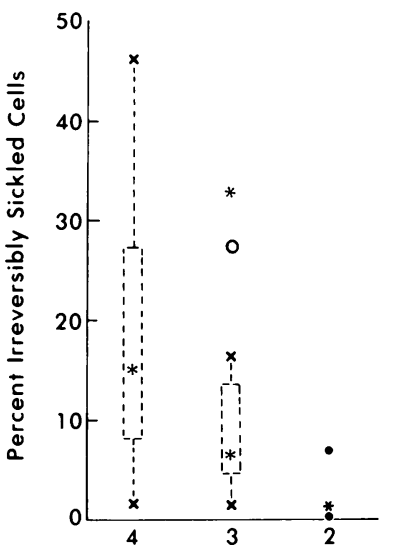

Number of $\alpha$-Globin Genes

Figure 1. Effect of $\alpha$-globin gene number on ISC counts. The percentage of sickle RBC that are ISC is shown at the left and the number of $\alpha$-globin genes characteristic of each group is shown below. The number of patients examined were $n=28$ for the group with four, $n=12$ for the group with three, and $n$ $=3$ for the group with two $\alpha$ globin genes. These data are displayed using boxplots (Methods). The boxes contain the middle $50 \%$ of the data (the interquartile range); the asterisk within the box is the median point; and except for the

outliers, the rest of the data points reside within the two crosses. The open circle represents an outlier that is further than one interquartile distance and the asterisk represents one that is further than 1.5 times the interquartile distance from the extremities of the box. In the twogene group, the asterisk represents the median data point and the other two points are shown by dots.

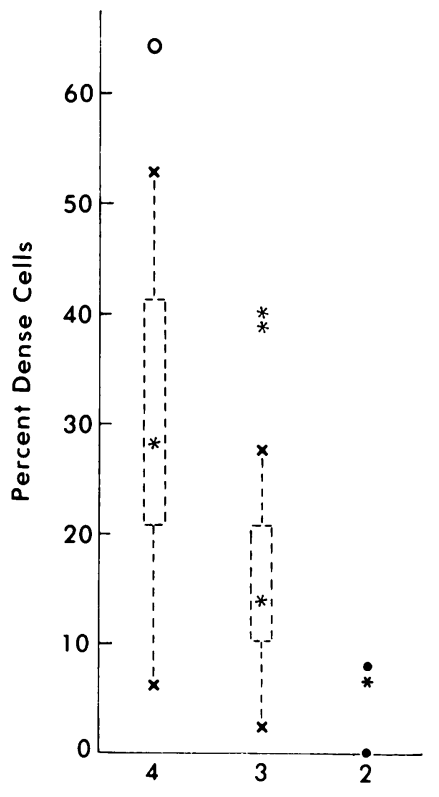

Figure 2. Effect of $\alpha$-globin gene number on the proportion of very dense sickle RBC. The fraction of $R B C$ with $d>1.1056 \mathrm{~g} / \mathrm{ml}$ is shown on the left and the $\alpha$ globin gene number characteristic of each group is shown below. The number of patients examined were $n$ $=26$ for the group with four, $n=13$ for the group with three, and $n$

$=3$ for the group with two $\alpha$-globin genes. See Fig. 1 and Methods regarding the boxplot method of displaying data. In the two-gene group, the asterisk represents the median data point and the other two points are shown

Number of $\alpha$-Globin Genes by dots.

DI in hypotonic medium reflects that sickle $\mathrm{RBC}$ are relatively dehydrated at physiologic osmolality (33), and contrasts sharply with the behavior of control RBC, which become overhydrated and even less deformable than sickle RBC from many sickle cell subjects at 210 mosM (Fig. 3).

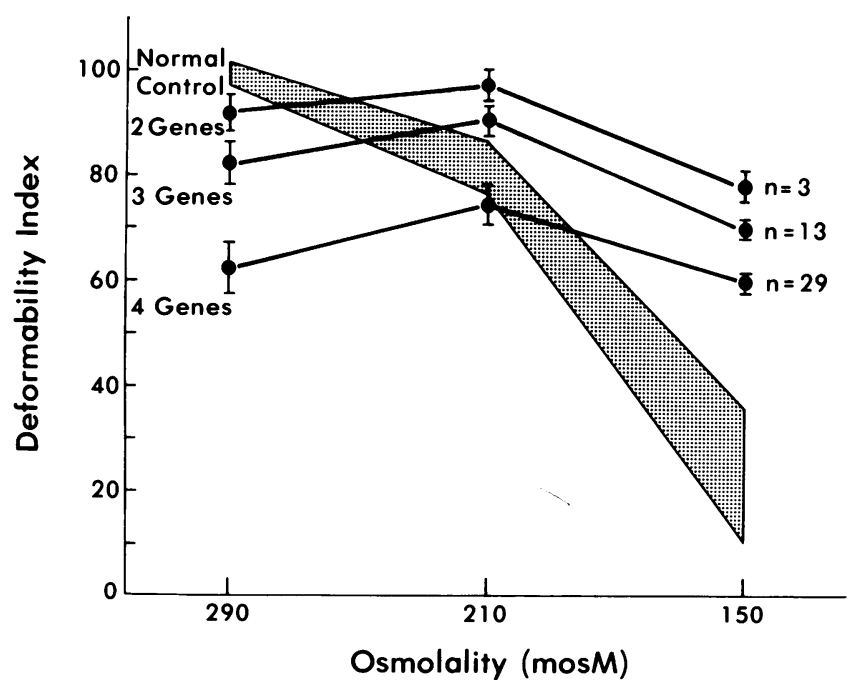

Figure 3. Effect of $\alpha$-globin gene number on the deformability of sickle RBC at three osmolalities. The percent DI is shown on the left (DI of sickle RBC/DI of normal RBC at $290 \mathrm{mosM}$ ), and the $\alpha$ globin gene number is indicated. The range of DI values for normal $\mathrm{RBC}$ at the designated osmolalities is indicated by the shaded area. In this figure, only the mean and SE for each group is shown for the sake of clarity. The numbers of patients examined is indicated on the right. 
With further osmotic hydration of sickle RBC at 150 mosM, the $\mathrm{RBC}$ from the nonthalassemic subjects still remained significantly $(P<0.01)$ less deformable than those from either group of subjects with $\alpha$-thalassemia; yet, RBC from all subjects had markedly decreased percent DI compared with their deformability at 210 and $290 \operatorname{mosM}$ (Fig. 3). This reduced deformability reflected cellular overhydration and resembled the effect of overhydration on control RBC (Fig. 3).

At each osmolality, an inverse relationship was observed between $\alpha$-globin gene number and sickle RBC deformability.

Effect of $\alpha$-globin gene number on density and $M C H C$ of sickle $R B C$. Representative subjects with sickle cell anemia having four, three, or two $\alpha$-globin genes, respectively, were selected on the basis of having ISC counts characteristic for their $\alpha$-globin genotypes. ISC count and whole blood MCHC for each subject were as follows: (two genes) $0 \%$ and $30.9 \mathrm{~g} / \mathrm{dl}$; (three genes) $12 \%$ and $35.2 \mathrm{~g} / \mathrm{dl}$; and (four genes) $35 \%$ and 35.7 $\mathrm{g} / \mathrm{dl}$. The density distribution of these sickle RBC and RBC from a normal control with homozygous $\mathrm{Hb} \mathrm{A}$ and $\mathrm{MCHC}$ equal to $34.3 \mathrm{~g} / \mathrm{dl}$ on twelve-step analytical gradients is shown in Fig. 4, and the percentage of $\mathrm{RBC}$ in each gradient fraction is shown in Fig. 5. These data again demonstrate a direct relationship between the proportion of most dense sickle RBC and the $\alpha$-globin gene number, i.e., the presence of four $\alpha$-globin genes is associated with more very dense RBC than is the presence of three or two genes. The finding of increased numbers of dense

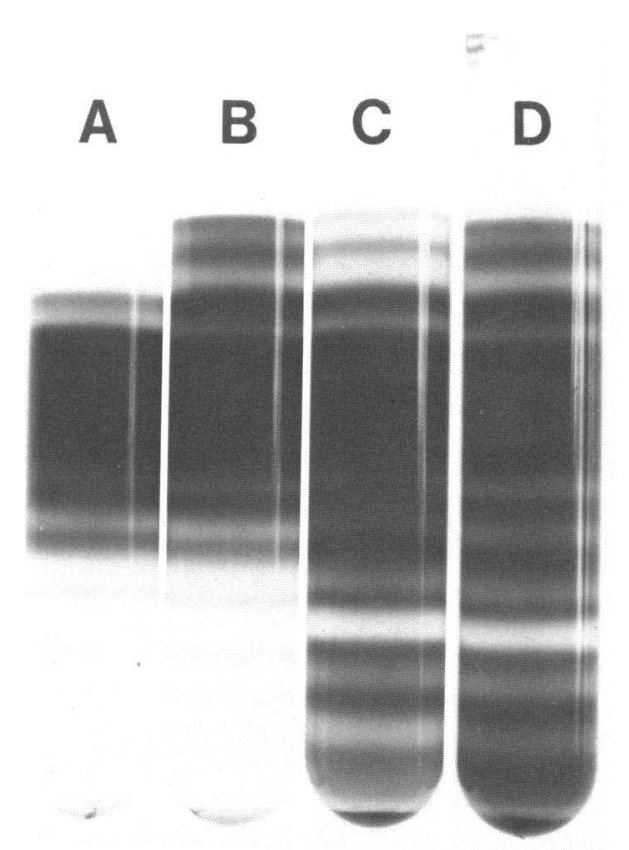

Figure 4. Effect of $\alpha$-globin gene number on the density of sickled RBC. Analytic Stractan gradients containing RBC from $(A)$ control subject with $\mathrm{Hb} \mathrm{AA}$ and four $\alpha$-globin genes, $(B) \mathrm{Hb}$ SS subject with two $\alpha$-globin genes, $(C) \mathrm{Hb}$ SS subject with three $\alpha$-globin genes, and (D) Hb SS subject with four $\alpha$-globin genes.
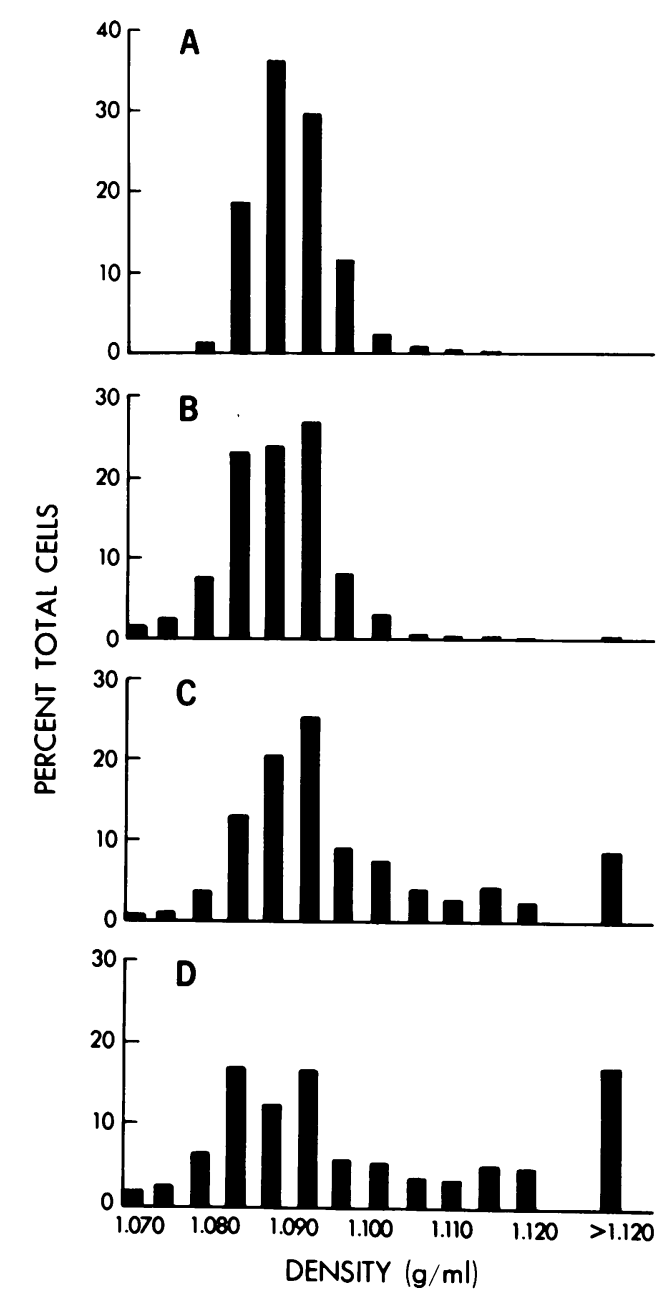

Figure 5. Effect of $\alpha$-globin gene number on the density of sickle RBC. The percentage of RBC isolated from the fractions of the analytical Stractan gradients pictured in Fig. 4 is shown on the left and the densities of the gradient layers at which each fraction stopped are shown below. The RBC are again from $(A)$ control subject with $\mathrm{Hb}$ AA and four $\alpha$-globin genes, $(B) \mathrm{Hb}$ SS subject with two $\alpha$-globin genes, $(C) \mathrm{Hb}$ SS subject with three $\alpha$-globin genes, and (D) Hb SS subject with four $\alpha$-globin genes.

sickle $\mathrm{RBC}$ in the nonthalassemic subject is compatible with the associations of ISC number and proportion of "dense" $\mathrm{RBC}$ (25), ISC number and severity of anemia (14), and the presence of four $\alpha$-globin genes and more severe anemia $(7,8)$. The presence of greater numbers of the lower density sickle RBC in the nonthalassemic subject reflects greater numbers of reticulocytes (29) in response to more severe hemolytic anemia $(7,8)$.

The average measured MCHC of sickle $\mathrm{RBC}$ in the different fractions of the eight-step preparative gradients is shown in Table I. There was a clear increase in MCHC associated with greater sickle RBC density. 
Table I. Relationship between Sickle RBC Density and MCHC

\begin{tabular}{lll}
\hline Density of fraction & MCHC & Evaluable samples \\
\hline$g m / m l$ & $g m / d l$ & No. \\
$>1.120$ & $>43.0$ & 2 \\
1.115 & 42.8 & 1 \\
1.110 & 40.5 & 3 \\
1.105 & 35.2 & 3 \\
1.100 & 34.7 & 2 \\
1.092 & 30.7 & 3 \\
1.084 & 29.1 & 2 \\
1.076. & 25.0 & 1 \\
\end{tabular}

Effect of $\alpha$-globin gene number on density of nonsickle $R B C$. The effect of $\alpha$-globin gene number on the density of RBC from subjects with homozygous $\mathrm{Hb} \mathrm{A}$, who had four, three, two, or one $\alpha$-globin gene(s), respectively, as analyzed on eleven-step analytical gradients, also demonstrated a direct effect of $\alpha$-globin gene number on RBC density (Fig. 6). This effect was of lesser magnitude per gene than that seen in sickle $R B C$, and the difference between the density distributions of the subjects with four and three $\alpha$-globin genes was so subtle as to be barely discernible in Fig. 6. Even in the absence of the severe cation fluxes $(34)$ and cellular dehydration $(27,28,29)$ that occur in sickle RBC, lower numbers of $\alpha$-globin genes were associated with larger fractions of low density $\mathrm{RBC}$.

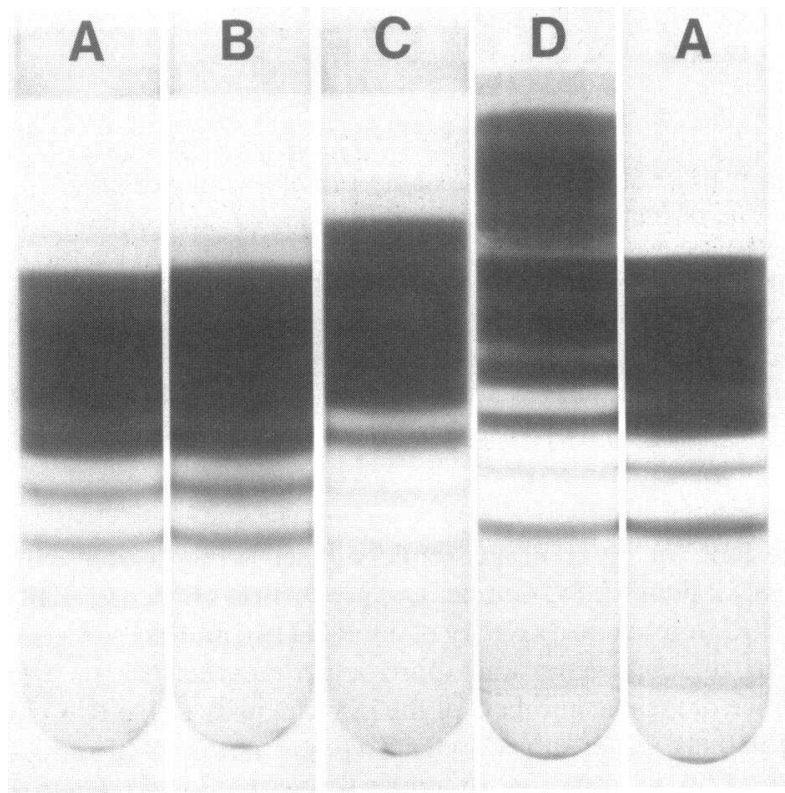

Figure 6. Effect of $\alpha$-globin gene number on nonsickle RBC density. Analytic Stractan gradients containing RBC from subjects homozygous for $\mathrm{Hb} \mathrm{A}$ with $(A)$ four $\alpha$-globin genes, $(B)$ three $\alpha$ globin genes, $(C)$ two $\alpha$-globin genes, and $(D)$ one $\alpha$-globin gene.
Effect of $\alpha$-globin gene number vs. RBC density on RBC deformability. We used blood from the same sickle and control subjects that we had used for the density gradient experiment summarized in Fig. 4 to measure RBC deformability as a continuous function of osmolality (Fig. 7). Fig. $7 A$ shows that the DI values for total $\mathrm{RBC}$ at 290 mosM were inversely related to $\alpha$-globin gene number (as previously observed for DI measurements at fixed osmolality, Fig. 3) and that over virtually the entire osmotic range, the DI values of sickle $\mathrm{RBC}$ retained this inverse relationship to $\alpha$-globin gene number. While these three subjects exhibited clear differences in their $\alpha$-globin gene numberdependent RBC deformability, subjects with more similar ISC counts had less different DI curves (data not shown). The curves of all three sickle subjects were substantially shifted to lower

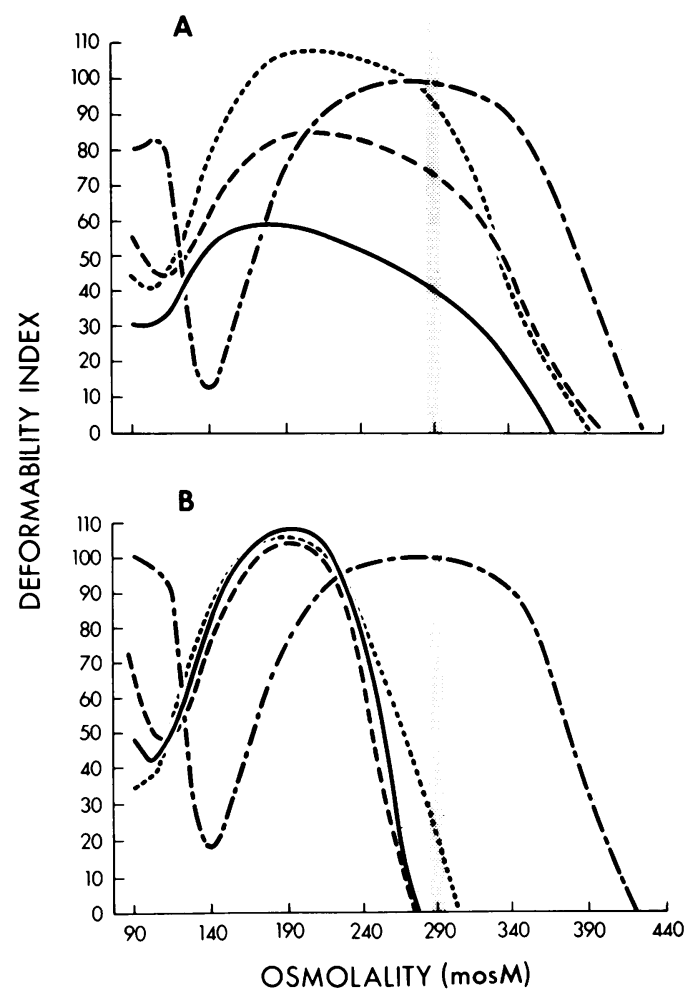

Figure 7. Effects of $\alpha$-globin gene number and of RBC density on RBC deformability. The curves represent the DI determined while the osmolality of the medium in which RBC were suspended was changed over the linear gradient shown below. Isotonicity is indicated by the vertical cross-hatched bars.

The osmotic gradient deformability curves are represented by dot dash lines (- - -) for the control RBC, dotted lines ( $\cdots)$ for sickle $\mathrm{RBC}$ from the subject with two $\alpha$-globin genes, dashed lines (- - -) for sickle RBC from the subject with three $\alpha$-globin genes, and solid lines $(-)$ for sickle RBC from the subject with four $\alpha$-globin genes. $(A)$ contains the osmotic gradient deformability curves for the total RBC from these subjects. $(B)$ contains the deformability curves for $\mathrm{RBC}$ fractions with the $d 1.087-1.092 \mathrm{~g} / \mathrm{ml}$ that were isolated from these subjects. 
osmolality compared with the normal curve; this is a finding that we have previously shown to indicate RBC dehydration (30).

Fig. $7 B$ shows the osmotic gradient deformability curves for $\mathrm{RBC}$ subpopulations of the same density isolated on preparative Stractan gradients from the same blood samples. These RBC were taken from the interface between the layers with densities of 1.087 and $1.092 \mathrm{~g} / \mathrm{ml}$, and thus, had the same density and $\mathrm{MCHC}(33.0 \mathrm{~g} / \mathrm{dl} \pm 0.8 \mathrm{SD})$. Independent of $\alpha$-globin gene number, the three sickle samples demonstrated almost identical deformability over the entire osmotic range. However, these curves were also shifted to lower osmolality compared with the control curve, despite all four samples having the same RBC density and MCHC. The hypotonic portion of this shift indicates a decreased osmotic fragility of the sickle RBC due to an increased surface area-to-volume ratio. The fact that the sickle DI curves reached a higher maximum value than the normal curve suggests that part of the increased osmotic resistance of sickle RBC is attributable to an increase in surface area (30), possibly as a result of diminished $\mathrm{RBC}$ membrane remodeling in sickle subjects who are asplenic or functionally asplenic (35). The leftward shift of the descending hypertonic arm of the sickle curves demonstrated dehydration-dependent decreased RBC deformability which may be related to increased intracellular viscosity, to polymerization of $\mathrm{Hb} \mathrm{S}$, or to $\mathrm{Hb}$-mediated membrane damage. Whatever the mechanism, the uniformity of the DI curves for sickle RBC of the same density, as contrasted with the substantial differences of the curves for the total sickle RBC samples, clarifies one point; the primary effect of $\alpha$-globin gene number on the deformability of total sickle $\mathrm{RBC}$ populations is to determine the $\mathrm{RBC}$ density distribution rather than to modulate the deformability of sickle $\mathrm{RBC}$ that have the same density.

\section{Discussion}

We have found that $\alpha$-thalassemia has a salutary effect on the ISC number, the proportion of "dense" RBC, and the deformability of sickle RBC; this is a set of interrelated variables, each of which is predicted to relate to the clinical severity of sickle cell disease. Our results indicate that the primary effect of $\alpha$ thalassemia on these RBC properties is to regulate the fraction of $\mathrm{RBC}$ that achieves a high cell density, which are a fraction of cells known to contain the ISC (13) and to be the least deformable (17). We base this conclusion mainly on the differences in the deformabilities of the total $\mathrm{RBC}$ populations (Fig. $7 \mathrm{~A}$ ) and of the RBC fractions of equal density (Fig. $7 \mathrm{~B}$ ) from representative sickle subjects with different numbers of $\alpha$ globin genes. These differences of deformability demonstrate that the greater rigidity of sickle $\mathrm{RBC}$ from nonthalassemic subjects is not related to a lesser degree of deformability of RBC of the same density, but to a greater fraction of RBC of high density, as demonstrated also in Figs. 2, 4, and 5. While nonsickle
RBC also demonstrated a direct relationship between $\alpha$-globin gene number and RBC density, the differences in density relative to gene number were much less than those of sickle RBC. It appears that a general effect on RBC density is inherited with the $\alpha$-globin gene number and that this effect is amplified in sickle $\mathrm{RBC}$, probably as a result of sickling-induced cation and water losses (34); these processes together apparently result in the significant differences in sickle RBC density and deformability that we observed.

Among the suggested determinants of the variable clinical severity of sickle cell anemia, the ISC has been the most extensively studied. This cell, traditionally defined as a sickle RBC whose elongated shape does not revert to normal upon oxygenation (36), also has been characterized in several other ways. It has lost cations and water $(27,28,29,34)$ to become among the most dense sickle RBC (13). It also is among the fraction of sickle RBC that are the least deformable (17), have the lowest content of $\mathrm{Hb} \mathrm{F} \mathrm{(13),} \mathrm{contain} \mathrm{the} \mathrm{highest} \mathrm{levels} \mathrm{of} \mathrm{calcium} \mathrm{(37,}$ 38 ), and have the greatest $\mathrm{Hb} \mathrm{S}$ polymer content at any given oxygen tension (39). Isolation of the membrane skeleton of ISC has revealed that it retains the irreversibly sickled shape of the intact cell, suggesting a permanent membrane skeletal defect (40). Once generated, the ISC is destined to an early demise (13). Our data suggest that the mechanism by which $\alpha$-thalassemia retards the development of these pathologic properties is related to the powerful deterrent effect that lowering the intracellular $\mathrm{Hb} \mathrm{S}$ concentration has on $\mathrm{Hb} \mathrm{S}$ polymerization $(3,4)$ and to the resultant retardation of the sickle-unsickle process on which the loss of cations and water (35), the increased cell density, and the generation of ISC (41) may depend.

We previously reported that the presence of $\alpha$-thalassemia results in higher $\mathrm{Hb} \mathrm{F}$ levels in subjects with homozygous sickle cell anemia (7), but studies of larger numbers of patients were unable to confirm this association (8). It is unlikely that this trend in $\mathrm{Hb} F$ levels among our patients is responsible for our current findings, despite the beneficial effects of $\mathrm{Hb} \mathrm{F}$ in sickle cell disease (42). Although we report only three subjects with two $\alpha$-globin genes, one of these has only modest elevations in $\mathrm{Hb} \mathrm{F}$ levels and yet is clearly among those with the fewest ISC and dense RBC and the best RBC deformability.

Despite these associations, we (data not shown) and others (8) have not found all aspects of clinical severity to correlate directly with the $\alpha$-globin gene number. This suggests that confounding influences on clinical severity are not affected by the presence of $\alpha$-thalassemia and its beneficial effect on $\mathrm{Hb} \mathrm{S}$ polymerization. One of these variables which relates to the different rheologic determinants of blood flow within blood vessels of different size, in fact, appears to be adversely affected by the presence of $\alpha$-thalassemia. It is axiomatic that painful crises result from microvascular occlusion caused by sickling, but the actual size of the vessels involved remains undefined. While individual $\mathrm{RBC}$ rigidity affects primarily capillary blood flow (16), whole blood viscosity, which is directly related to the hematocrit level (17), is the major determinant of large vessel flow 
(43). The findings that cerebral thromboses in sickle patients are associated with large vessel occlusion (44), and that aseptic necrosis occurs more commonly in subjects with microcytosis and higher hemoglobin levels (12), suggest that in sickle cell disease vaso-occlusion is not limited to the microcirculation. Thus, the elevated hematocrit associated with $\alpha$-thalassemia may be detrimental to rheology in vessels of larger size and this may partially counter the beneficial effects on individual RBC deformability.

The effects that $\alpha$-thalassemia may exert on a set of sickle RBC membrane phenomena which may affect vaso-occlusive severity are less predictable. Sickle RBC have increased susceptibility to oxidation of membrane phospholipids (45), a finding that may relate to the sickling-dependent translocation of phosphatidylserine and phosphatidylethanolamine from the inner to the outer membrane leaflet (46) and to the thromboplastic activity (47) and cell membrane-liposome interaction (48) generated by this translocation. The similarities that exist between the adherence of sickle RBC to liposomes (48) and to endothelial cells $(49,50)$ suggest that the severity of vaso-occlusion, which correlates with endothelial adherence (51), may also be related to the membrane lesions enumerated above.

It is even conceivable that enhanced damage to the sickle RBC membranes may occur as a result of the fundamental defect of $\alpha$-thalassemia, the imbalanced globin chain synthesis due to diminished $\alpha$-chain production $(1,52)$. The oxidative radicals that result in peroxidation of membrane lipids appear to be generated by hemichrome (or heme), which is adherent to the interior of sickle RBC membranes (53). Of the various globin chains, the $\beta$-globin chain with the sickle mutation $\left(\beta^{s}\right)$ is among those with a high affinity for the membrane interior (54). Thus, the excess, unpaired $\beta^{s}$ chains within sickle RBC from subjects with $\alpha$-thalassemia might result in larger amounts of globin and heme binding to the membrane interior, enhancement of membrane lipid peroxidation, and perhaps even promotion of RBC adherence. Alternatively, these membrane phenomena may be confounding influences of severity that are unaffected by $\mathrm{Hb} \mathrm{S}$ polymerization and $\alpha$-thalassemia.

$\alpha$-Thalassemia impairs the generation of those pathological properties of sickle RBC that are directly related to $\mathrm{Hb} \mathrm{S}$ polymerization and reduces the resultant degree of anemia. Its possible detrimental effects on the rheology of sickle blood, on the generation of membrane lipid peroxidation, and on enhancing sickle RBC adherence phenomena may diminish the anticipated improvement in the clinical status of sickle patients. These interactions require further definition.

Note added in proof. Since this manuscript originally was submitted, a report was published in this journal (55), the results of which are compatible with our data. When sickle RBC are separated by density gradients, their rheologic properties ex vivo are directly related to their density and $\mathrm{MCHC}$ whether the RBC are oxygenated or deoxygenated. In vitro measurements of bulk viscosity demonstrated a similar relationship except that reticulocyte-rich RBC fractions had greater viscosity than what would have been expected from these low density RBC.

\section{Acknowledgments}

We are grateful to Ms. Jennie Schacht and Ms. Leslie-Ann Burnette for excellent assistance in the preparation of this manuscript, to Dr. Bernard Forget for the kind gift of plasmid JW 101, and to Dr. Haiganoush Preisler for statistical analysis. We thank Drs. William Mentzer, William Lande, Bertram Lubin, Robert Johnson, and Elliot Vichinsky for allowing us to study their patients.

This work was supported by grants HL 20985 and AM 26263 from the National Institutes of Health.

\section{References}

1. Bunn, H. F., B. G. Forget, and H. M. Ranney. 1977. Human Hemoglobins. W. B. Saunders Co., Philadelphia.

2. Dean, J., and A. N. Schechter. 1978. Sickle cell anemia: molecular and cellular basis of therapeutic approaches. N. Engl. J. Med. 299:752763; 804-811; 863-870.

3. Hofrichter, J., P. D. Ross, and W. A. Eaton. 1974. Kinetics and mechanism of deoxyhemoglobin $S$ gelation: a new approach to understanding sickle cell disease. Proc. Natl. Acad. Sci. USA. 71:4864-4868.

4. Noguchi, C. T., D. A. Torchia, and A. N. Schechter. 1980. Determination of deoxyhemoglobin $\mathrm{S}$ polymer in sickle erythrocytes upon deoxygenation. Proc. Natl. Acad. Sci. USA. 77:5487-5491.

5. Steinberg, M. H., B. J. Dreiling, F. S. Morrison, and T. F. Necheles. 1973. Mild sickle cell disease: clinical and laboratory studies. JAMA (J. Am. Med. Assoc.). 224:317-321.

6. Dozy, A. M., Y. W. Kan, S. H. Embury, W. C. Mentzer, W. C. Wang, B. Lubin, J. R. Davis Jr., and H. M. Koenig. 1979. Alpha globin gene organization in Blacks precludes the severe form of alpha thalassemia. Nature (Lond.). 280:605-607.

7. Embury, S. H., A. M. Dozy, J. Miller, J. R. Davis Jr., K. M. Kleman, H. Preisler, E. Vichinsky, W. N. Lande, B. H. Lubin, Y. W. Kan, and W. C. Mentzer. 1982. Concurrent sickle-cell anemia and $\alpha$ thalassemia: effect on severity of anemia. N. Engl. J. Med. 306:270274.

8. Higgs, D. R., B. E. Aldridge, J. Lamb, J. B. Clegg, D. J. Weatherall, R. J. Hayes, Y. Grandison, Y. Lowrie, K. P. Mason, B. E. Serjeant, and G. R. Serjeant. 1982. The interaction of alpha-thalassemia and homozygous sickle-cell disease. N. Engl. J. Med. 306:1441-1446.

9. Brittenham, G. M., A. N. Schechter, and C. T. Noguchi. 1983. Hemoglobin $S$ polymerization predicts the severity of the sickling syndromes. Clin. Res. 31:480A (Abstr.).

10. Mears, J. G., H. M. Lachman, D. Labie, and R. L. Nagel. 1983. Alpha thalassemia is related to prolonged survival in sickle cell anemia. Blood. 62:286-290.

11. Hayes, R. J., P. I. Condon, and G. R. Serjeant. 1981. Haematologic factors associated with proliferative retinopathy in homozygous sickle cell disease. Brit. J. Ophthalmol. 65:29-35.

12. Hawker, H., H. Neilson, R. J. Hayes, and G. R. Serjeant. 1982. Haematologic factors associated with avacular necrosis of the femoral head in homozygous sickle cell disease. Brit. J. Haematol. 50:29-34.

13. Bertles, J. F., and P. F. A. Milner. 1968. Irreversibly sickled erythrocytes. A consequence of the heterogeneous distribution of hemoglobin types in sickle-cell anemia. J. Clin. Invest. 47:1731-1740.

14. Serjeant, G. R., B. E. Serjeant, and P. F. Milner. 1969. The irreversibly sickled cell: a determinant of haemolysis in sickle cell anemia. Brit. J. Haematol. 17:527-533. 
15. Chien, S. 1970. Abnormal rheology of oxygenated blood in sickle cell anemia. J. Clin. Invest. 49:623-634.

16. La Celle, P. L. 1975. Pathologic erythrocytes in the capillary microcirculation. Blood Cells. 1:269-284.

17. Chien, S. 1977. Rheology of sickle cells and erythrocyte content. Blood Cells. 3:283-303.

18. Clark, M. R., N. Mohandas, and S. B. Shohet. 1980. Deformability of oxygenated irreversibly sickle cells. J. Clin. Invest. 65:189196.

19. Cartwright, G. E. 1968. Diagnostic Laboratory Hematology. Grune \& Stratton, Inc., New York. Fourth ed. 441.

20. Southern, E. M. 1975. Detection of specific sequences among DNA fragments separated by gel electrophoresis. J. Mol. Biol. 98:503517.

21. Wilson, J. T., L. B. Wilson, J. K. de Riel, L. Villa-Komaroff, A. Efstratiadis, B. G. Forget, and S. Weissman. 1978. Insertion of synthetic copies of human globin genes into bacterial plasmids. Nucleic Acids Res. 5:563-581.

22. Maniatis, T., A. Jeffrey, and D. G. Kleid. 1975. Nucleotide sequence of the rightward operator of phage $\lambda$. Proc. Natl. Acad. Sci. USA. 72:1184-1188.

23. Alter, B. P., S. C. Goff, G. D. Efremov, M. E. Gravely, and T. H. J. Huisman. 1980. Globin chain electrophoresis: a new approach to the determination of $\mathrm{G}_{\gamma}: \mathrm{A}_{\gamma}$ ratio in fetal haemoglobin and to studies of globin synthesis. Brit. J. Haematol. 44:527-534.

24. Higgs, D. R., S. E. Y. Goodbourn, J. S. Wainscot, J. B. Clegg, and D. J. Weatherall. 1981. Highly variable regions of DNA flank the human $\alpha$-globin genes. Nucleic Acids Res. 9:4213-4224.

25. Clark, M. R., N. Mohandas, S. H. Embury, and B. H. Lubin. 1982. A simple laboratory alternative to irreversibly sickled cell (ISC) counts. Blood. 60:659-662.

26. Bessis, M., and N. Mohandas. 1975. A diffractometric method of the measurement of cellular deformability. Blood Cells. 1:307-313.

27. Bessis, M., and N. Mohandas. 1977. Laser diffraction patterns of sickle cells in fluid shear fields. Blood Cells. 3:229-239.

28. Glader, B. E., S. E. Lux, A. Muller-Soyano, O. S. Platt, R. D. Propper, and D. G. Nathan. 1978. Energy reserve and cation composition of irreversibly sickle cells in vivo. Brit. J. Haematol. 40:527-532.

29. Clark, M. R., R. C. Unger, and S. B. Shohet. 1978. Monovalent cation composition and ATP and lipid content of irreversibly sickled cells. Blood. 51:1169-1178.

30. Clark, M. R., N. Mohandas, and S. B. Shohet. 1983. Osmotic gradient ektacytometry: comprehensive characterization of red cell volume and surface maintenance. Blood. 61:899-910.

31. Miller, R. G., Jr. 1981. Least significant difference test (Fisher). In Simultaneous Statistical Inference. R. G. Miller, Jr., editor. Springer Verlag, Inc., New York. 90-94.

32. Tukey, J. 1977. Easy summaries/numerical and graphical. In Exploratory Data Analysis. Addison-Wesley Publishing Co., Inc., Reading, MA. 27-56.

33. Mohandas, N., M. R. Clark, M. S. Jacobs, and S. B. Shohet. 1980. Analysis of factors regulating erythrocytes deformability. J. Clin. Invest. 66:563-573.

34. Glader, B. E., and D. G. Nathan. 1978. Cation permeability alterations during sickling and generation of irreversibly sickle cells. Blood. 51:983-989.

35. Lux, S. E., and K. M. John. 1977. Isolation and partial characterization of a high molecular weight red cell membrane protein complex normally removed by the spleen. Blood. 50:625-641.

36. Diggs, L. W., and J. Bibb. 1939. The erythrocyte in sickle cell anemia. Morphology, size, hemoglobin content, fragility, and sedimentation rate. JAMA (J. Am. Med. Assoc.). 112:695-701.

37. Eaton, J. W., T. D. Skelton, H. S. Swofford, C. E. Kolpin, and H. S. Jacob. 1973. Elevated erythrocyte calcium concentrations in sickle cell disease. Nature (Lond.). 246:105-106.

38. Eaton, J. W., H. S. Jacob, and J. G. White. 1979. Membrane abnormalities of irreversibly sickled cells. Semin. Hematol. 16:52-64.

39. Noguchi, C. T., D. A. Torchia, and A. N. Schechter. 1983. Intracellular polymerization of sickle hemoglobin. Effects of cell heterogeneity. J. Clin. Invest. 72:846-852.

40. Lux, S. E., K. M. John, and M. J. Karnovsky. 1976. Irreversible deformation of the spectrin-actin lattice in irreversibly sickled cells. $J$. Clin. Invest. 58:955-963.

41. Jensen, M., S. B. Shohet, and D. G. Nathan. 1973. The role of red cell energy metabolism in the generation of irreversibly sickled cells in vitro. Blood. 42:835-842.

42. Serjeant, G. R. 1975. Fetal haemoglobin in homozygous sickle cell disease. Clin. Haematol. 4:109-122.

43. Horne, M. K. 1981. Sickle cell anemia as a rheologic disease Am. J. Med. 70:288-298.

44. Stockman, J. A., M. A. Nigro, M. M. Mishkin, and F. A. Oski. 1972. Occlusion of large cerebral vessels in sickle-cell anemia. N. Engl. J. Med. 287:846-849.

45. Lubin, B., and D. Chiu. 1980. Abnormal susceptibility of sickle erythrocytes to lipid peroxidation. In Red Blood Cells and Lens Metabolism. S. Srivastava, editor. Elsevier North-Holland, Inc., New York. 159-162.

46. Lubin, B., D. Chiu, J. Bastacky, B. Roelofsen, and L. L. M. VanDeenen. 1981. Abnormalities in membrane phospholipid organization in sickled erythrocytes. J. Clin. Invest. 67:1643-1649.

47. Chiu, D., B. Lubin, B. Roelofsen, and L. L. M. VanDeenen. 1981. Sickled erythrocytes accelerate clotting in vitro: an effect of abnormal membrane lipid asymmetry. Blood. 58:398-401.

48. Schwartz, R. S., N. Duzgunes, D. T.-Y. Chiu, and B. Lubin. 1983. Interaction of phosphatidylserine-phosphatidylcholine liposomes with sickle erythrocytes. Evidence for altered membrane surface properties. J. Clin. Invest. 71:1570-1580.

49. Hebbel, R. P., O. Yamada, C. F. Moldow, H. S. Jacob, J. G. White, and J. W. Eaton. 1980. Abnormal adherence of sickle erythrocytes to cultured vascular endothelium. Possible mechanism for microvascular occlusion in sickle cell disease. J. Clin. Invest. 65:154-160.

50. Hoover, R., R. Rubin, G. Wise, and R. Warren. 1979. Adhesion of normal and sickle erythrocytes of endothelial monolayer cultures. Blood. 54:872-876.

51. Hebbel, R. P., M. A. B. Boogaerts, J. W. Eaton, and M. H. Steinberg. 1980. Erythrocyte adherence to endothelium in sickle-cell anemia: a possible determinant of disease severity. N. Engl. J. Med. 302:992-995.

52. Weatherall, D. J., and J. B. Clegg. 1981. The thalassemia syndromes. Blackwell Publisher, Oxford. Third ed. 875.

53. Hebbel, R. P., J. W. Eaton, M. Balasingam, and M. H. Steinberg. 1982. Spontaneous oxygen radical generation by sickle erythrocytes. $J$. Clin. Invest. 70:1253-1259.

54. Bank, A., G. Mears, R. Weiss, J. V. O'Donnell, and G. Natta. 1974. Preferential binding of $\beta^{s}$ globin chains associated with stroma in sickle cell disorders. J. Clin. Invest. 54:805-809.

55. Kaul, D. K., M. E. Fabry, P. Windisch, S. Baez, and R. L. Nagel. 1983. Erythrocytes in sickle cell anemia are heterogeneous in their rheological and hemodynamic characteristics. J. Clin. Invest. 72:22-31. 